\title{
Decision Making Processes for a Pregnant Woman Admitted to the Accident and Emergency Department Requiring Emergency Diagnostic X-ray - A Case Study
}

\author{
S. ISMANTO
}

\begin{abstract}
The objective of this study is to apply the decision-making processes for a pregnant woman who was involved in a motor vehicle accident and admitted to a private middle-class hospital in the capital of Indonesia requiring radiologic X-ray examination. It also aims to examine and evaluate the patient who was in her 20th week of gestation in order to provide her with the best emergency care, diagnostic investigations and treatments.

The descriptive, normative and prescriptive models of decision-making are demonstrated. The descriptive model used intuition, while the normative model used decision trees as decision options and lastly the prescriptive decision used the information processing theory (IPT) to decide on the best emergency care, diagnostic investigations and treatments for the patient.

The IPT dominated the decision-making process; hence an X-ray examination was done that was safe for the fetus and the childbearing mother. Decision option was not used since the patient was in pain and could not understand much of the procedure that was explained. Intuition helped in the decision-making in order to ensure safe and effective practice.
\end{abstract}

Key words: Decision-making; case study; pregnancy X-ray; A\&E; information processing theory

This case study applies the decision-making processes for a pregnant woman who experienced a motor vehicle accident and admitted to a private middle-class hospital in the capital of Indonesia requiring radiologic $\mathrm{X}$-ray examination. It also aims to examine and evaluate the pregnant admitted patient in her 20th weeks of gestation in order to provide her with the best emergency care, diagnostic investigations and treatments.

The descriptive, normative and prescriptive models of decision-making was demonstrated and therefore conclude with a sound decision (Shaban 2012).
Ethics of justice were considered and this case study maintained anonymity of patient's, healthcare professionals' and hospital's name. The purpose is to make a world view on how a sound decision-making is demonstrated in a fast-paced environment.

\section{BACKGROUND}

$\mathrm{X}$-ray is a form of electromagnetic radiation with very high frequency and energy (Eskandar et al.2010), with a wavelength shorter so as to have a fairly high permeability of the material. Therefore, X-rays can be used as diagnostic and therapeutic management in medical radiology.

Academy Technical Radio-Diagnostic and Radiotherapy Nusantara, Indonesia

* Corresponding author (e-mail: faizmanto78@gmail.com) 
Radiology services in the capital of Indonesia have sufficient modalities such as conventional X-ray, fluoroscopy, computerized tomography scans, magnetic resonance imaging, and radiotherapy; thus they have sufficient healthcare professionals at work. They operate for 24-hours for emergency cases and can immediately investigate medical problem.

The optimization of protection and safety, when applied to the exposure of workers and of members of the public, and of carers and comforters of patients undergoing radiological procedures, is a process for ensuring that the magnitude and likelihood of exposures and the number of individuals exposed are as low as reasonably achievable, with economic, societal and environmental factors taken into account (Agency 2014). Protection procedure aims to prevent the occurrence of deterministic effects in individuals by keeping doses below the threshold and to minimize the risk of stochastic effects (Eskandar et al. 2010). Thousands of pregnant patients and medical radiation workers are exposed to radiation each year. Lack of knowledge is responsible for great anxiety and probably unnecessary termination of many pregnancies (Cousins 2008).
It is known that diagnostic X-ray examinations for pregnancy should not be performed unless the expected benefit to the mother or the embryo / fetus exceeds the known risks (Damilakis et al. 2002).

The accepted background cumulative dose of ionising radiation during pregnancy is $5 \mathrm{rad}(50 \mathrm{mGy})$ which is much more than the exposure dose of most of the diagnostic radiological examinations (Eskandar et al. 2010). The risk of microcephaly and severe mental retardation with high exposure begins at 10 weeks of gestation. This risk is greatest at 10-17 weeks, with less risk at 18-27 weeks. There is no proven risk before 10 weeks or after 27 weeks even with doses exceeding 500 mGy. Furthermore, a non-threshold, linear, dose-related association between severe mental retardation and radiation has been found following exposure during weeks 10-17 of gestation, so that even very low doses cause a slight increase in mental retardation incidence. This trend reaches $40 \%$ at $100 \mathrm{rad}(1000 \mathrm{mGy})$, although it is not statistically significant at doses generated by diagnostic radiographs. Nevertheless, until more data are available delineating potential fetal risk, it is prudent

Table 1. Possible effects of acute doses of radiation and estimated threshold doses (Eskandar et al. 2010).

\begin{tabular}{l|lccccc}
\hline $\begin{array}{c}\text { Gestational } \\
\text { age }\end{array}$ & \multicolumn{1}{|c}{ Possible effect } & 1 mGy & 10 mGy & 50 mGy & $500 \mathrm{mGy}$ & $\begin{array}{c}\text { Threshold dose } \\
\text { (mGy) }\end{array}$ \\
\hline Up to 1 week & Miscarriage & Nil & Nil & Nil & Possible & $100^{47}$ \\
$2-6$ weeks & Miscarriage & Nil & Nil & Nil & Possible & $250-500^{47}$ \\
& Gross malformations & Nil & Nil & Nil & Possible & $200^{47}$ \\
$10-17$ weeks & Mental retardation & Nil & Nil & Nil & $20 \%$ & None \\
& IQ score decline & $(-)$ & $(-)$ & $(-)$ & 15 points & Non-threshold \\
& Gross malformations & Nil & Nil & Nil & Possible & $500^{47}$ \\
$18-27$ weeks & Mental retardation & Nil & Nil & Nil & $5 \%$ & $120^{5}$ \\
& IQ score decline & $(-)$ & $(-)$ & $(-)$ & 4 points & $120^{5}$ \\
Throughout & Fetal growth restriction & Nil & Nil & Nil & Possible & $200-250^{48}$ \\
& Childhood cancer & $0.002 \%$ & $0.002 \%$ & $0.1 \%$ & $1 \%$ & None \\
& Fetal adult cancer & $0.006 \%$ & $0.060 \%$ & $0.3 \%$ & $3 \%$ & None \\
\hline
\end{tabular}


to delay non-urgent radiographs during the sensitive period of 10-17 weeks of gestation. Table 1 highlights the possible effects of X-ray to pregnancy in accordance to its gestationional age.

\section{The Case}

A 35 years old pregnant patient at her 20 weeks of gestation was admitted to the accident and emergency department with suspected fracture of the left ankle as a result of a motor vehicle accident. Statement was taken by emergency triage healthcare professionals.

Patients came to the Emergency Room with the condition of left ankle pain thus it could not be freely moved. Physician on duty diagnosed and palpated the left ankle which appeared swollen and sore with bluish discolouration.

\section{Upon Admission to the Accident and Emergency}

The physician instructed the nurse in charge to give intravenous Lactated Ringers fluid, 500 milliliters at 5 drops per minute that might help replace electrolytes that were lost during an evidence of vasoconstriction as an effect of pain and hooked to an oxygen mask at 1 milliliter of air to help relax the muscles, thus helped relieve the pain. A measurement of blood pressure with the result 140/80 millimeters of mercury, saturated partial oxygenation result of $90 \%$ and heart rate and rhythm of 120 beats per minute at regular beats were assessed. The physician also instructed the midwife on duty in the delivery room to help check the fetal condition by conducting a Doppler ultrasonography examination and referred it to the obstetrician in charge. The Doppler examination result showed a fetal heart rate of 134 beats per minute which was anticipated by obstetricians to be a normal fetal condition. In addition to the obstetrician referral, the accident and emergency department physician in charge referred the patient to the orthopedic surgeons since a fracture was suspected.
The obstetrician examining the state of the woman's uterus after Doppler was released and says that the fetus remained in good position and confirmed that the patient was at her 20 weeks gestation. The orthopedic palpated the ankle and intuitively diagnosed as a completed displaced fracture of the left fibula proximal cruris. However, a radiologic X-ray would verify the palpated complete displaced fracture.

\section{After 8 Hours in the Accident and Emergency Department}

The author being the radiographer understood that if X-ray was not done the suspected fracture of the left ankle of the patient might have a delayed anticipated surgical operation. In addition, the author also knew that if a fracture was present, and surgery was delayed and complications could be anticipated to occur hence it might lead to amputation. Table 2 highlights the complications of fractures if not treated, managed and cared for within 8 hours from the time of injury.

The decision was made after having consultation between the radiographer, radiologist and medical physicist to require a written request form for X-ray examination from the orthopedic surgeon was the initial step taken during the first 8 hours. A conventional routine and lateral ankle mortis was required because of low radiation position as was specifically recommended by the obstetricians. The author being the radiographer who would perform radiologic examinations for the pregnant mother should consult the physician.

Finally, the patient would be asked by the author to fill out a consent form for a radiological examination and approval action letter from the orthopedic surgeon for the left ankle X-ray.

However, the author still discussed decision options found on Figure 1, in the form of a decision tree with orthopedic surgeon. These 
Table 2. highlighted the complications of fractures if not treated (Høiness \& Strømsøe 1999).

\begin{tabular}{l|l}
\hline Types of closed fractures & \multicolumn{1}{|c}{ Complications if untreated within 8 hours } \\
\hline Comminuted & Embolism, deep vein thrombosis and crush syndrome \\
Displaced & Embolism, systemic hypovolemia and compartment syndrome \\
Greenstick & Volkmann's ischemia and fat embolism \\
Spiral & Volkmann's ischemia and fat embolism \\
Oblique & Volkmann's ischemia and fat embolism \\
Transverse & Volkmann's ischemia and fat embolism \\
Impacted & Embolism and compartment syndrome \\
\hline
\end{tabular}

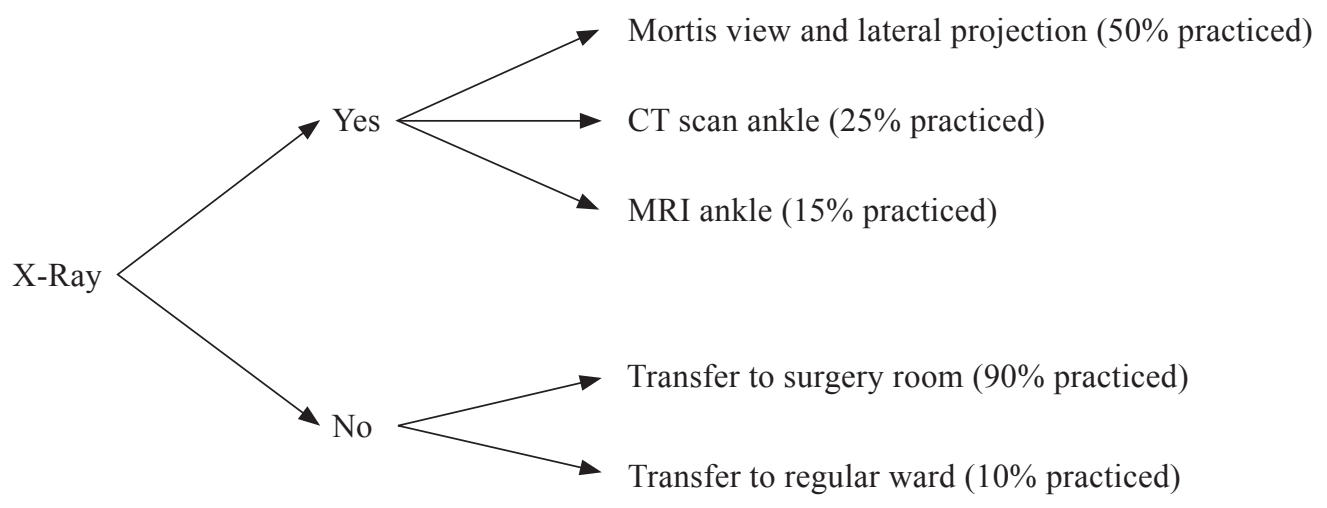

Figure 1. The decision tree divided into probabilities.

options were used for suspected fractures among pregnant women that was based on clinical guidelines in outlining options.

\section{Upon Transfer to the Radiology Room}

The mortis view and lateral projection was decided upon by the orthopedic surgeon. The author took the patient to the X-ray department and placed her in the supine position to take the X-ray of the left ankle, in the anteriorposterior - basic (Mortice projection) and lateral view, the mid-section and then rotated the feet in towards the inside (endo-rotation) by 20 degrees. The elevation to the lateral malleolus parallel to the medial malleolus of the patient's left ankle was positioned (in case the legs stays straight without rotation, the lateral malleolus, and the lower medial malleolus are readily positioned), in order to show a clear, two space joint both laterally and medially, using $18 \times 24$ centimeter film tapes placed under the ossa calcaneus, central ray perpendicular to the vertical central point on the ankle joint and lateral thalo-cruralis with 90 centimeter film focus distance (FFD) (Whitley et al. 2005).

The author covered the patient with lead Apron 0.5 millimeters $\mathrm{Pb}$ thickness up to the thigh as a form of radiation protection to reduce the scattering of radiation (Kim et al. 2012). The exposure factor made as low as possible 50 kilo voltages peak $(\mathrm{kVp})$ at 6 milliamperes seconds (mAs) without using stationary grid (Whitley et al. 2005). The X-ray results were printed by the author and delivered to the radiologist to be interpreted. Radiologists gave a written report, that a visible completed displaced fracture of 

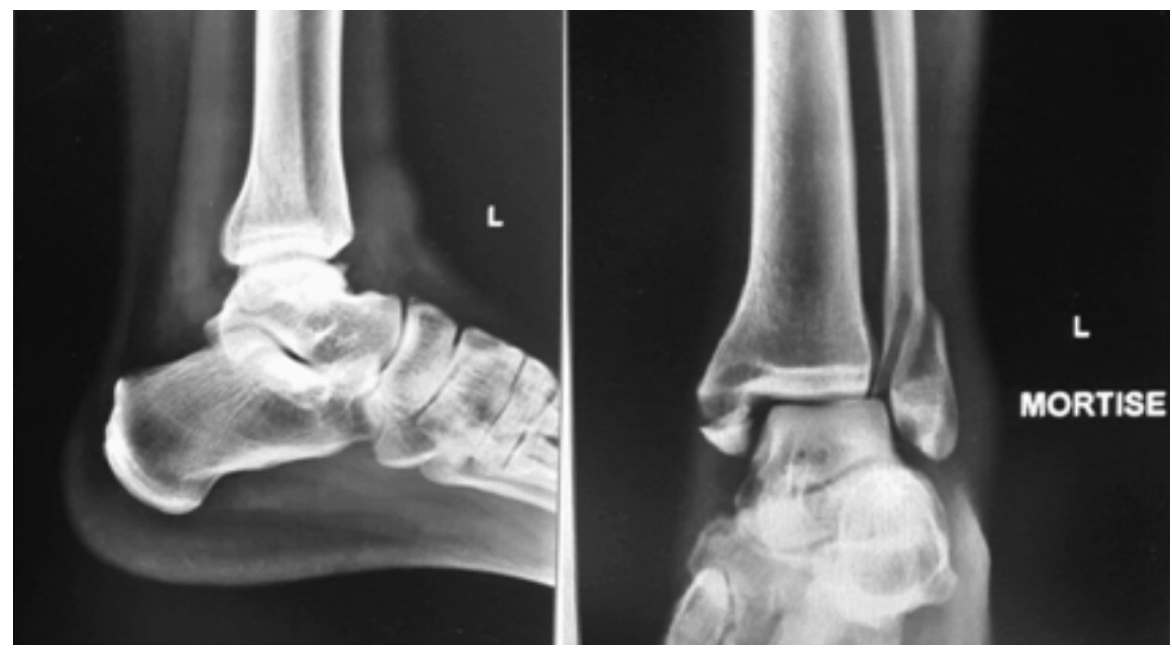

Figure 2. The left mortise view with fracture (see appendix for radiologist's interpretation).

the left lateral and medial malleolus was seen on the X-ray film as intuitively hypothesized.

Table 3 shows the clinical guidelines for radiographers providing X-rays for a pregnant woman that was a skill demonstrated by the author in this case study.

Doses for the same procedures vary widely between patients and hospitals. However, the absorbed dose of the embryo or the fetus where the X-ray beam does not directly irradiate them, such as maternal skull or chest X-ray, is extremely low therefore, the further the target area from the embryo or fetus, the less the exposure and risk of radiation and vice versa (Eskandar et al. 2010). The American College of Obstetrics and Gynecology (ACOG) states that exposure to $<5$ rads is not associated with an increase in fetal anomalies or pregnancy loss. For instance, a chest X-ray gives of $<0.001$ rads, while a pelvic radiograph (Hart 2005). Table 4 shows radiation doses for ankle (lower extremity ) X-ray examination is safe.

Table 3. Clinical guidelines for radiographers (Whitley et al. 2005; Kim et al. 2012).

\begin{tabular}{l|l}
\hline Stage 1: Re-evaluation & $\begin{array}{l}\text { Patient was transferred to the examination table and was positioned. Physicians' } \\
\text { orders are transcribed for the target organ to be filmed. }\end{array}$ \\
$\begin{array}{l}\text { Stage 2: Transcription } \\
\text { of physicians' order }\end{array}$ & $\begin{array}{l}\text { The request was to film the antero-posterior - basic } \\
\text { (Mortice projection) imagery of the ankle and lateral projection. The film } \\
\text { tapes with the size of } 18 \times 24 \text { centimeters is placed under the ossa calcaneus. }\end{array}$ \\
$\begin{array}{l}\text { Stage 3: Proper } \\
\text { positioning }\end{array}$ & $\begin{array}{l}\text { The position of the object (ankle) is slightly stretched, to the central ray } \\
\text { perpendicular to the vertical beam of the X-ray with the central point on } \\
\text { the thalo-cruralis joint and ankle laterally with FFD at } 90 \text { centimeters gap. }\end{array}$ \\
Stage 4: Provisions of & $\begin{array}{l}\text { The patient was covered with lead apron at thickness of } 0.5 \text { millimeters of } \\
\text { lead up to the thigh as a form of radiation protection. This will reduce the } \\
\text { scattering of radiation. The time factor is made as low as possible exposure of } \\
\text { peak kilo voltage at less than 50:6 mAs without using the lisolm grid board. }\end{array}$ \\
\hline
\end{tabular}


Table 4. Approximate fetal radiation doses of common diagnostic procedures (McCollough et al. 2007).

\begin{tabular}{|c|c|c|c|}
\hline Procedure & $\mathrm{mSv}$ & Mean dose mGy (rad)* & Maximum dose $\mathrm{mGy}(\mathrm{rad})^{*}$ \\
\hline \multicolumn{4}{|l|}{ X-Ray } \\
\hline Abdomen & 1 & $1.4(0.14)$ & $4(0.4)$ \\
\hline Kidney, ureter, and bladder & 1.7 & $2.9(0.29)$ & $15(1.5)$ \\
\hline Chest & 0.02 & Less than $0.01(0.001)$ & Less than $0.01(0.001)$ \\
\hline $\begin{array}{l}\text { Intravenous urogram/ } \\
\text { pyelogram }\end{array}$ & 10 to 20 & $1.7(0.17)$ & $\begin{array}{c}10(1) ; 0.37 \text { to } 2.64 \\
(0.037 \text { to } 0.264)\end{array}$ \\
\hline Lumbar spine & 1.3 & 1.7 (0.17); $3.4(0.34)$ & Less than $0.01(0.01)$ \\
\hline Pelvis & 0.7 & $1.1(0.11) ; 3.4(0.34)$ & $4(0.4) ; 22(2.2)$ \\
\hline Skull & 0.07 & $\begin{array}{c}\text { Less than } 0.01(0.001) \\
0.04(0.004)\end{array}$ & Less than $0.01(0.001)$ \\
\hline Thoracic spine & 0.7 & Less than $0.01(0.001)$ & $\begin{array}{c}\text { Less than } 0.01(0.001) \text {; } \\
0.03(0.003)\end{array}$ \\
\hline Dental & & $\begin{array}{l}\text { Less than } 0.001(0.0001) \text {; } \\
\text { Less than } 0.01(0.001)\end{array}$ & \\
\hline Upper/lower extremity & Less than 0.01 & $0.01(0.001)$ & \\
\hline Mammogram & 0.6 & Less than $0.05(0.005)$ & $0.2(0.02)$ \\
\hline Hip & 0.3 & & 0.51 to $1.4(0.051$ to 0.14$)$ \\
\hline \multicolumn{4}{|l|}{ Computed Tomography } \\
\hline Abdomen & 10 & 8 & $8(0.8) ; 7.6(0.76)$ \\
\hline Chest & 8 & $0.06(0.006)$ & $\begin{array}{c}0.96(0.096) \\
\text { less than } 1(0.1)\end{array}$ \\
\hline Hand & & Less than $0.005(0.0005)$ & Less than $0.005(0.0005)$ \\
\hline Lumbar spine & & $2.4(0.24) ; 7.5(0.75)$ & $8.6(0.86) ; 40(4)$ \\
\hline Pelvis** & 7.1 & $25(2.5)$ & $79(7.9)$ \\
\hline Head & 2.3 & Les than $0.005(0.0005)$ & Les than $0.005(0.0005)$ \\
\hline Pelvimetry & & $0.2(0.02)$ & $0.4(0.04)$ \\
\hline \multicolumn{4}{|l|}{ Fluoroscopy } \\
\hline Upper GI & & $1.1(0.11)$ & $5.8(0.58) ; 0.56(0.056)$ \\
\hline Barium enema** & 7 & $6.8(0.68) ; 10(1)$ & $24(2.4) ; 130(1.3)$ \\
\hline Barium swallow & 15 & $1.1(0.11)$ & $(0.58)$ \\
\hline
\end{tabular}

* Duplicate values represent different estimations in the literature.

**Highlighted rows indicate potential of more than $50 \mathrm{mGy}$.

When managing the pregnant patient, the major role of the medical physicist was to estimate absorbed dose to the conceptus of a pregnant patient from selected diagnostic or interventional procedures, either prospectively or retrospectively. The physicist also consulted with the radiologist regarding risk associated with radiation and means by which this risk could be reasonably limited.

The accepted background cumulative dose of ionising radiation during pregnancy is $5 \mathrm{rad}(50 \mathrm{mGy})$, which is much more than the exposure dose of most of the diagnostic 
radiological examinations. Current evidence suggested that there was no increased risk of major malformations, growth restriction or miscarriage from radiation doses of $<5 \mathrm{rad}$ (50 mGy), compared with background risks in non-exposed foetuses which were $3 \%, 4 \%$, and $15 \%$, respectively. There was also evidence that gross congenital malformations would not be increased in a human pregnant population exposed to a dose of $<20 \mathrm{rad}$ (200 mGy), which was considered the threshold dose. A dose of $>250 \mathrm{mGy}$ might be associated with a $0.1 \%$ risk of fetal malformation. However, microcephaly, microphthalmia, genital and skeletal malformations, cataracts and small for gestational age have been clearly observed in human embryos and fetuses exposed to $>1000$ mGy (Eskandar et al. 2010).

\section{METHODOLOGY}

This section examines and evaluates how the three basic models of decision-making - the descriptive, prescriptive and normative - were applied.

A descriptive decision is characterized by understanding how individuals make judgments and decisions focusing on the actual conditions, contexts, ecologies and environments in which they are made (Shaban 2012). An advantage of the descriptive models is the adequacy in supporting Assumptions made about decisionmaking processes with relevant examples from a suitable period of observation (Shaban 2012). An example is intuition (Bell et al. 1988).

A normative model in decision-making process is characterized by rational, logical and scientific procedures supported by clear or probable evidence (Harrison 1996; Offredy 1998; Shaban 2012). Statistical analysis with decision trees of large-scale experimental and survey research is representative of a population target where the findings are information sources in a normative decision (Bell et al. 1988). The advantages enable decision-makers to minimize judgment errors (Thompson \& Dowding 2002) especially when patients or relatives are key decision makers (Say \& Thomson 2003).

Lastly, a prescriptive model uses information processing theory (IPT) as a prescriptive tool to assist practitioners in enhancing decision tasks to analyze sources, principles and findings of previous research or clinical guidelines with algorithms (Shaban 2012). Table 5 summarizes the three decision-making models.

\section{The Prescriptive Decision-making}

The IPT used clinical guidelines for radiographers found on Table 3 . The guideline started with re-evaluation of the physician's order, followed by the transcription of the order, followed by the proper positioning and ends with provisions of safety for the patient (Whitley et al. 2005).

\section{IPT Step One: Cue Acquisition}

Physical examination such as assessing the heart rate and rhythm, blood pressure, saturated partial oxygen in percentage and threshold of pain were acquired in order to determine the vital signs of the patient (Hart 2005). Biophysiologic apparatuses used blood pressure and stethoscope for auscultation to see the possibility of gestational hypertensions, and irregular rhythm of the heart. Doppler is also used to assess the fetal heartbeat and its gestational week (Hart 2005). These cues were acquired in order to hypothesize on exposure of the embryo or fetus to high dose ionizing radiation could potentially lead to some adverse health effects. However, the radiation dose to the embryo or fetus that is likely to result from any diagnostic procedures should present no risk of causing any deterministic effects such as foetal death, malformation, growth retardation, or mental retardation (Osei \& Darko 2012). But more importantly, palpation of the left ankle to determine fracture was an important cue that was lastly acquired. 
Table 5. Summary of three decision-making models (Bell et al. 1988; Shaban 2012; Dioso, 2015).

\begin{tabular}{|c|c|}
\hline \multicolumn{2}{|r|}{ Normative model } \\
\hline Characteristics & Rational, logical, scientific, evidence based decisions. \\
\hline Information sources & $\begin{array}{l}\text { Statistical analysis of large-scale experimental and survey research which is } \\
\text { representative of a target population where the findings can be applied. }\end{array}$ \\
\hline Examples & Clinical trials that test the efficacy of new medicines and treatments. \\
\hline Advantages & $\begin{array}{l}\text { Enable decision-makers to predict and explain the outcomes of decisions and } \\
\text { minimize judgment errors }\end{array}$ \\
\hline \multicolumn{2}{|r|}{ Prescriptive model } \\
\hline Characteristics & Frameworks or guidelines designed to enhance specific decision tasks. \\
\hline Information sources & $\begin{array}{l}\text { Principles and findings of previous scientific research (associated with } \\
\text { normative models). }\end{array}$ \\
\hline Examples & IPT using clinical guidelines \\
\hline Advantage & Research-based and evidence-based decision-making. \\
\hline \multicolumn{2}{|r|}{ Descriptive model } \\
\hline Characteristics & $\begin{array}{l}\text { Understanding how individuals make judgments and decisions focusing on } \\
\text { the actual conditions, contexts, ecologies, and environments in which they } \\
\text { are made. }\end{array}$ \\
\hline Information sources & $\begin{array}{l}\text { Observation, description and analysis of how decisions are made by managers } \\
\text { and professionals in relation to their day-to-day responsibilities. }\end{array}$ \\
\hline Examples & Intuition and pattern recognition \\
\hline Advantage & $\begin{array}{l}\text { Adequacy in supporting assumptions made about decision-making processes } \\
\text { with relevant examples from a suitable period of observation. }\end{array}$ \\
\hline
\end{tabular}

\section{IPT Step Two: Hypothesis Generation}

A complete displaced ankle fracture was hypothesized when an oedema was noted and the patient could not move the legs without feeling pain. Therefore if it was not immediately diagnosed with X-ray, surgery could be delayed hence, it would cause decay resulting to an anticipated amputation. Physicians hypothesized that an X-ray should be done as a guideline before deciding to undergo surgery. It was also hypothesized that the fetus would be in safe condition as verified by the Doppler ultrasonography result.

An amount of 0.001 rads doses of lower extremity (ankle) was recommended to the patient for 20 weeks gestation. While the accepted background cumulative dose of ionising radiation during pregnancy was 5 $\operatorname{rad}(50 \mathrm{mGy})$, which was much more than the exposure dose of most of the diagnostic radiological examinations. The risk of microcephaly and severe mental retardation with high exposure began at 10 weeks of gestation. This risk was greatest at 10-17 weeks, with less risk at 18-27 weeks.

\section{IPT Step Three: Interpretation of Cues}

The pregnant patient was having a left complete displaced ankle fracture verified by X-ray. In addition, she primarily needed plain Lactated Ringers solution as intravenous drip in order to replace the electrolytes that were lost because of the experienced pain during the vehicular accident. In addition, intravenous fluid replacement was necessary to increase her electrolyte count before surgery, especially for pregnant patients. 
Lastly, pain must be controlled before undergoing X-ray, since positioning the ankle might induce more anticipated pain. Therefore oxygen was important to be provided in order to relax the muscle that was de-oxygenized after the accident.

\section{IPT Step Four: Hypothesis Evaluation}

In this step, the patient at 20 weeks gestation must be made safe from the X-ray radiation. Radiation protection in diagnostic radiography was essential if medical exposure to ionising radiation was to be maintained at a level of minimal acceptable risk. The concept of risk was an important one and it was essential that we reduced risks to the patient and staff through the justification, optimisation and limitation of radiation exposures. Adapted from National Radiation Protection Board (1994) Justification: No practice involving exposure to radiation should be adopted unless it produces net benefit to those exposed or to society. Optimisation: Radiation doses and risks should be kept as low as reasonably achievable, economic and social factors being taken into account; constraints should be applied to dose or risk to prevent an unacceptable degree of exposure in any particular circumstance. Limitation: The exposure of individuals should be subject to dose or risk limits above which the radiation risk would be deemed unacceptable (Hardy \& Boynes 2008).

$\mathrm{X}$-ray are the most common and widely available diagnostic imaging technique. X-ray could show if the bone was broken and whether there was displacement (the gap between broken bones). They also showed how many pieces of broken bone there were. X-rays might be taken of the leg, ankle and foot to make sure nothing else was injured. CT scan type of scan create a cross-section image of the ankle and sometimes done of further evaluate the ankle injury. It was especially useful when fracture extends into the ankle joint. MRI Scan provide high resolution images of both bones and soft tissues, like ligaments. For some ankle fractures, an MRI scan may be done to evaluate the ankle ligaments (Michelson 2003).

\section{The Normative Decision-making}

Decision options were presented to the orthopedic surgeon. Understanding the principles, diagnostic value and safety of imaging to the fetus and the mother, and of various diagnostic modalities at different stages of pregnancy, is essential to select the most appropriate imaging modality (Eskandar et al. 2010), MRI was preferred to CT or conventional X-rays for a large number of medical problems, particularly those connected with injury or disease of the central nervous system (Eskandar et al. 2010).

\section{The Descriptive Decision-making}

By intuition, the author trusted that the patient was positive with fracture of the left ankle. This was why in the decision option found on Figure 1, it recommended surgery without $\mathrm{X}$-ray. It was also because the findings of the vital signs and palpation examination of the left ankle, the patient was positive to have a complete displaced fracture.

It is important to trust an intuition if it is also based on recognized patterns of previously encountered similar cases (Dioso 2015). The author being an expert radiographer could intuitively perceive signs of fracture just by means of interview. The author has also intuitively hypothesized at the late stage of the patient's admission to the accident and emergency ( 8 hours after) that signs of fracture is evident. Therefore trusting the intuition is just the same as looking back at the patterns of previously encountered cases (Dioso 2015).

However, it is important to take caution using intuition during the early part of consultation. This is because an intuition is a substandard way of decision-making that is 
only characterized by a shallow understanding of actual events and conditions taking place (Dioso 2015). Figure 2 illustrates how to trust an intuition.

That was why surgery was suggested to be done straight away, since by intuition, and recognizing patterns of previously encountered cases, the author could trust this decision as an alternative option. This option (surgery without $\mathrm{X}$-ray) might be trusted that was the lesser evil as also one of the norms usually done in this hospital.

\section{DISCUSSION}

This section discusses the effectiveness of clinical guidelines and the decision options that were used in deciding for the best diagnostic test to be used for the patient in a fast paced environment.

One of the guidelines says that fracture requires immediate surgical operation that cannot be delayed, and requires an X-ray result (Stiell et al. 1993). However, the decision should not be rushed and must be done with good clinical judgment.

It was expected that healthcare workers should not be overly prescriptive or descriptive in a fast paced environment. That was why in the accident and emergency department, decisions had to used all for three processes to limit mistakes.

In this case, we can see that clinical guidelines majorly influenced the decisions by all healthcare professionals who were involved in treating and diagnosing the patient. Likewise, the clinical guidelines affected the patient's right to decide what is best for herself. Patients themselves should be the key decision makers (Quill \& Holloway 2011). However, in this case, the orthopedic surgeons instigate a decision hence, in the end the patient agreed because she was in the state of feeling intolerable pain.

It is also a good decision from the physicians to uphold their Hippocratic Oath that doctors should do no harm for their patients (Osei \& Darko 2012), which is why sometimes, doctors in the hospital settings always decides on behalf of their patients in a fast paced environment. The case presented a typical decision-making that was manipulated by physicians in an emergency situation. Rushing a decision gives no avenues for the patients to think and decide for themselves (Daniels \& Nicoll 2011).

Lastly, physicians should use evidencebased counseling to eliminate the perception of the risk of unsound decision making (Pregnancy

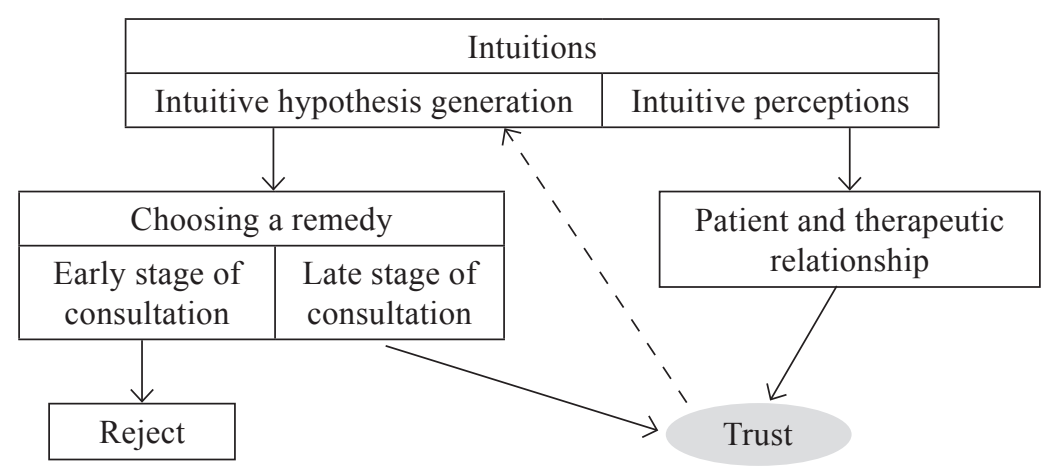

Figure 3. How to use an intuition (Dioso 2015). 
2000), and not just mitigating patients to immediately sign their consents. A clinical guideline (complications of fractures) in this case was used to mitigate the pregnant patient to sign the consent for X-ray since the guideline mentions about morbid outcomes if diagnostic procedures are delayed.

There are recommendations for clinical decision makers which they might want to consider in the future as they face the same or similar cases.

It was recommended that patients on private hospitals in Indonesia who were not so much capable of paying their hospital bills must limit usage of technology such as X-ray machines. Intuitions were recommended especially if the chief complaint was recognized to be similar to previously encountered cases. In this way, the impact of decisions gave more benefits than harm to the patient.

It was still however recommended in a fast paced environment that the use of clinical guidelines should be considered as the safest decision making process. Explaining to the patient the advantages of each diagnostic examination in order for her to understand clearly the options provided was the better decision-making process.

\section{CONCLUSION}

It was therefore concluded that in this study, IPT dominated the decision-making process; hence an X-ray examination was done that was safe for the fetus and the childbearing. Decision options were somehow incorrectly practiced since the patient was in pain, and was not capable of understanding the options presented, that was why the doctors were the ones who decided on her behalf. Therefore, the decision maker must always be in control psychologically and intellectually in order to demonstrate a sound decision.
Solving problems using prescriptive decision-making, in this case was somehow better if it was not affected mainly by clinical guidelines. Broadening perspectives using decision trees to create a mental framework must consider all options in order to turn away from frame blindness, especially in a fast-paced environment.

Decision-making should see all sides of the problem before making a decision so that patients feel satisfied and still be safe both physiologically and psychologically.

\section{ACKNOWLEDGEMENT}

The valuable assistance of Regidor III is much appreciated for the supervision of this study.

Date of submission: January 2016
Date of acceptance: March 2016

\section{REFERENCES}

Bell, DE et al. 1988, Decision making: descriptive, normative, and prescriptive interactions, Cambridge University Press.

Cousins, C 2008, 'Medical radiation and pregnancy', Health Physics, vol. 95, no. 5, pp. 551-553.

Damilakis, J et al. 2002, 'Embryo/fetus radiation dose and risk from dual X-ray absorptiometry examinations', Osteoporosis International, vol. 13, no. 9, pp. 716-722.

Daniels, R \& Nicoll, L 2011, Contemporary medicalSurgical nursing, 2nd edn, Delmar Cengage Learning, New York.

Dioso, R 2015, 'Decision-making processes for a do-not-resuscitate poisoned pediatric patient admitted to the department of emergency and medical services - a case study.' ASEAN Journal on Science and Technology for Development, vol. 32, no. 1, pp. 31-51.

Eskandar, O et al. 2010, 'Safety of diagnostic imaging in pregnancy. Part 1: X-ray, nuclear medicine investigations, computed tomography and contrast media', The Obstetrician \& Gynaecologist, vol. 12 , no. 2 , pp. $71-78$. 
Eskandar, O et al. 2010, 'Safety of diagnostic imaging in pregnancy, Part 2, Magnetic resonance imaging, ultrasound scanning and Doppler assessment', The Obstetrician \& Gynaecologist, vol. 12 , no. 3 , pp. 171-177.

Hardy, M \& Boynes, S 2008, Paediatric radiography, John Wiley \& Sons.

Harrison, EF 1996, 'A process perspective on strategic decision making', Management Decision, vol. 34 , no. 1, pp. 46-53.

Hart, MA 2005, 'Help! My orthopaedic patient is pregnant!', Orthopaedic Nursing, vol. 24, no. 2, pp. 108-114.

Høiness, P \& Strømsøe, K 1999, 'The influence of the timing of surgery on soft tissue complications and hospital stay. A review of 84 closed ankle fractures', Annales Chirurgiae et Gynaecologiae, vol. 20, no. 11, pp. 687-694.

International Atomic Energy Agency Vienna 2014, Radiation protection and safety of radiation sources: international basic safety standards, International Atomic Energy Agency, Vienna.

International Commission on Radiological Protection 2000, 'Medical radiation (ICRP publication 84)', Annals of ICRP, vol. 30, no. 1 .

Kim, H et al. 2012, 'Evaluation of effectiveness of new design lead apron during pregnant X-ray chest PA', Journal of the Korean Society of Radiology, vol. 6, no. 6, pp. 441-445.

Michelson, JD 2003, 'Ankle fractures resulting from rotational injuries', Journal of the American
Academy of Orthopaedic Surgeons, vol. 11, no. 6, pp. 40-412.

Offredy, M 1998, 'The application of decision making concepts by nurse practitioners in general practice', Journal of Advanced Nursing, vol. 28, no. 5, pp. 988-1000.

Osei, EK \& Darko, J 2012, 'Foetal radiation dose and risk from diagnostic radiology procedures: a multinational study', in International Schoarly Research Notices (ISRN) Radiology, vol. 2013.

Quill, TE \& Holloway, R 2011, 'Time-limited trials near the end of life', Journal of the American Medical Association, vol. 306, no. 13, pp. 1483-1484.

Say, RE \& Thomson, R 2003, The importance of patient preferences in treatment decisionschallenges for doctors, British Medical Journal, vol. 327, vol. 7414, pp. 542-545.

Shaban, R 2012, 'Theories of clinical judgment and decision-making: a review of the theoretical literature', Australasian Journal of Paramedicine, vol. 3 , no. 1 , pp. 8 .

Stiell, IG et al. 1993, 'Decision rules for the use of radiography in acute ankle injuries," Health Care, vol. 13, pp. 15.

Thompson, C \& Dowding, D 2002, 'Decision making and judgement in nursing-an introduction", in Clinical Decision Making and Judgement in Nursing, Churchill Livingstone, Edinburgh.

Whitley, AS, et al. 2005, Clark's positioning in radiography, 12th edn, CRC Press. 